\title{
Assessment of Adulteration of Cosmetics Based on Vegetable Oils by GC-FID and Lipid Profile Using Direct Infusion Electrospray Ionization Mass Spectrometry (ESI-MS)
}

\author{
Jessica S. Pizzo, ${ }^{a}$ Marilia B. Galuch, ${ }^{a}$ Patrícia D. S. Santos, ${ }^{a}$ Oscar O. Santos, ${ }^{b}$ \\ Lorena Visentainer, ${ }^{c}$ Marcos N. Eberlin ${ }^{d}$ and Jesuí V. Visentainer ${ }^{*}, a$ \\ ${ }^{a}$ Departamento de Química, Universidade Estadual de Maringá (UEM), \\ 87020-900 Maringá-PR, Brazil \\ ${ }^{b}$ Programa de Pós-Graduação em Ciência de Alimentos, \\ Universidade Estadual de Maringá (UEM), 87020-900 Maringá-PR, Brazil \\ ${ }^{c}$ Hospital de Clínicas, Universidade Estadual de Campinas (UNICAMP), \\ 13083-888 Campinas-SP, Brazil \\ ${ }^{d}$ Laboratório ThoMSon de Espectrometria de Massas, Instituto de Química, \\ Universidade Estadual de Campinas (UNICAMP), 13083-970 Campinas-SP, Brazil
}

\begin{abstract}
Vegetable oils have properties that are beneficial to the human skin, and so, they are being used increasingly as ingredients of many cosmetic preparations; however, they are targets of adulteration. This study will evaluate the authenticity of Brazilian cosmetics based on vegetable oils (sesame, peanut, sunflower, and almonds) to determine the composition of fatty acids by gas chromatography with flame ionization detection (GC-FID) and the percentage of fatty acids in conjunction with chemometric treatments (principal component analysis), and lipid profiles using direct infusion electrospray ionization mass spectrometry (ESI-MS). The results obtained were compared with the respective pure vegetable oils. Of the seven brands analyzed, three were revealed as authentic, three were found to be adulterated with the addition of large amounts of soybean oil, and one showed no vegetable oils. These results demonstrate the relevance of quality control for cosmetics based on vegetable oils, which are more susceptible to adulteration owing to their higher cost when compared with vegetable oils such as soybean.
\end{abstract}

Keywords: soybean oil, lipid profile, cosmetics, vegetable oil, adulteration

\section{Introduction}

Vegetable oils are complex chemical mixtures containing mainly triacylglycerides (TAG) and small amounts of vitamins, pigments, free fatty acids, monoacylglycerides, and diacylglycerides. ${ }^{1}$

Vegetable oils have been applied to human skin for cosmetic purposes for a long time because of their beneficial properties. They protect against excessive water loss through the skin by forming a protective coat on the epidermis. Additionally, such oils activate the regeneration of the skin's lipid barrier, normalize skin metabolism, and reduce inflammation of the skin. ${ }^{2}$

The adulteration of vegetable oils with lower priced oils has become a common practice in Brazil and worldwide. ${ }^{3-5}$

*e-mail: jesuiv@gmail.com
For this reason, there is a continuing need to develop safe, accurate, rapid, and simple analytical techniques that prove the authenticity of vegetable oils for food, as well as those used as raw materials for the manufacture of cosmetics, to determine the quality and authenticity of cosmetic formulations.

The techniques traditionally used to evaluate the authenticity of vegetable and/or animal oils include: gas chromatography with flame ionization detection (GC-FID), used to determine the fatty acid composition; and direct infusion by electrospray ionization mass spectrometry (ESI-MS), suitable owing to its speed and simplicity in the preparation of the sample, has been used for the characterization of the lipid profile, as well as in monitoring lipid markers, to detect adulteration. ${ }^{4-7}$

In this study, cosmetics with a vegetable oil base (sesame, peanut, sunflower, and almonds) were analyzed 
to monitor frauds with the addition of low-cost vegetable oil, such as soybean oil. To achieve this, the fatty acid composition and lipid profiles of each cosmetic were obtained via GC-FID and ESI-MS, respectively, and compared with the results obtained for pure vegetable oil profile (the raw materials used for their manufacture) and soybean oil.

\section{Experimental}

\section{Samples}

Cosmetics (body oil type) of different brands available on the Brazilian market, consisting mainly or only of vegetable oils (composition on the label) were purchased; these oils were peanut, sweet almond, sesame, and sunflower.

To obtain the pure vegetable oils, peanut, sweet almond, sesame, and sunflower seeds were acquired from a local market in Maringá (Paraná, Brazil). In addition, refined soybean oils from three different brands were purchased from the same region (samples $\mathrm{SO} 1, \mathrm{SO} 2$, and $\mathrm{SO} 3$ ).

Table 1 presents information provided on the labels about the composition and any additional information about the analyzed cosmetics.

Table 1. Composition provided by labeling of cosmetics based on the oils analyzed

\begin{tabular}{|c|c|c|}
\hline Sample & $\begin{array}{l}\text { Vegetable lipid } \\
\text { source }\end{array}$ & $\begin{array}{c}\text { Composition and additional } \\
\text { information }^{\mathrm{a}}\end{array}$ \\
\hline S1 & sesame & $100 \%$ pure and natural \\
\hline SF1 & sunflower & $100 \%$ pure and natural \\
\hline SF2 & sunflower & $100 \%$ pure and natural \\
\hline P1 & peanut & $100 \%$ pure and natural \\
\hline P2 & peanut & $100 \%$ pure and natural \\
\hline A1 & almond & $\begin{array}{l}\text { glycine soybean oil, mineral oil, } \\
\text { fragrance, almond oil, tocopherol, } \\
\text { BHT }\end{array}$ \\
\hline A2 & almond & $\begin{array}{c}\text { mineral oil, almond oil, fragrance, } \\
\text { cyclometicone, caprylic/capric } \\
\text { triglycerides, tocopheryl acetate, } \\
\text { triclosan, BHT, CI 61565/CI 26100/CI } \\
60725 / \mathrm{CI} 47000\end{array}$ \\
\hline
\end{tabular}

aAvailable on the package label. BHT: dibutylhydroxytoluene; CI 61565: 1,4-bis ( $p$-tolylamino)anthraquinone; CI 26100: 1-(4-(phenylazo) phenylazo)-2-naphthol; CI 60725: 1-hydroxy-4-( $p$-toluidino) anthraquinone; CI 47000: 1,3-isobenzofurandione.

\section{Obtaining pure vegetable oils}

Vegetable oils were extracted by pressing, according to Ribeiro et $a l .{ }^{8}$ All seeds were previously dried in a fan oven at $50{ }^{\circ} \mathrm{C}$ for $14 \mathrm{~h}$. Then, the seeds were ground to obtain a fine flour that was placed in a stainless steel cylinder (Metal PEM, PHP 30 tons model), under a pressure of 10 tons, to extract the respective oils. These oils were used as references of pure oils with regard to their origin, originating in sesame, sunflower, peanut and sweet almond oil samples.

\section{Fatty acid composition by GC-FID}

Fatty acids methyl esters (FAME) were prepared according to Hartman and Lago $^{9}$ and modified by Maia and Rodriguez-Amaya. ${ }^{10}$

FAMEs were separated by a Thermo Scientific Trace Ultra 3300 gas chromatograph, equipped with flame ionization detector (FID), fused silica capillary column CP-7420 (Select FAME, $100 \mathrm{~m}$ size $\times 0.25 \mathrm{~mm}$ internal diameter and $0.25 \mu \mathrm{m}$ cyanopropyl thin film as stationary phase), and a split/splitless injector. The detector and injector operation temperatures were 250 and $230{ }^{\circ} \mathrm{C}$, respectively. The column temperature was programmed to $165{ }^{\circ} \mathrm{C}$ for $18 \mathrm{~min}$, followed by a ramp of $4{ }^{\circ} \mathrm{C} \mathrm{min}^{-1}$ up to $235^{\circ} \mathrm{C}$ for $20 \mathrm{~min}$. The gas flow rates used were $1.2 \mathrm{~mL} \mathrm{~min}^{-1}$ carrier gas $\left(\mathrm{H}_{2}\right), 30 \mathrm{~mL} \mathrm{~min}^{-1}$ of make-up gas $\left(\mathrm{N}_{2}\right)$, and 30 and $300 \mathrm{~mL} \mathrm{~min}^{-1}$ of the flame gases $\mathrm{H}_{2}$ and synthetic air, respectively. Samples were injected in split mode, with a 40:1 ratio. The injection volume was $1.0 \mu \mathrm{L}$, according to Figueiredo et al. ${ }^{11}$ and Silveira et al. ${ }^{5}$

FAMEs were identified by comparing the retention times of the sample constituents with relative analytical standards (FAME Mix, C4-C24, Sigma-Aldrich); the results were expressed as a relative percentage of total fatty acids, automatically determined by Chromquest ${ }^{\mathrm{TM}} 5.0$ software.

\section{Sample preparation for ESI(+)-MS and instrumental conditions}

The lipid samples were prepared according to Youzbachi et al..${ }^{12}$ with some modifications: $50.0 \mu \mathrm{L}$ of oil was diluted in $950.0 \mu \mathrm{L}$ of chloroform (Synth, São Paulo, Brazil). To $5.0 \mu \mathrm{L}$ of this solution, $1.0 \mathrm{~mL}$ of methanol/ chloroform 9:1 (v/v; HPLC grade, J.T.Baker ${ }^{\circledR}$, USA) and $20.0 \mu \mathrm{L}$ of $0.10 \mathrm{~mol} \mathrm{~L}^{-1}$ ammonium formate (prepared in methanol) were added.

In electrospray ionization operating in positive mode (ESI(+)-MS) analysis, TAG ionization in vegetable oil is favored via $[\mathrm{TAG}+\mathrm{H}]^{+}$and $[\mathrm{TAG}+\mathrm{Na}]^{+}$. Therefore, ammonium formate was used as an additive to mostly favor TAG ionization via $\left[\mathrm{TAG}+\mathrm{NH}_{4}\right]^{+}$, in order to obtain reproducible lipid profiles. ${ }^{4}$

To evaluate the lipid profiles by ESI(+)-MS, properly prepared samples were infused directly in a Xevo TQ-D ${ }^{\mathrm{TM}}$ 
triple quadrupole mass spectrometer (MS; Waters, Massachusetts, USA) equipped with electrospray ionization (ESI) in positive mode.

The lipid profile was obtained, comprising the mass/ charge $(\mathrm{m} / \mathrm{z})$ range of $100-1200$ in triplicate. The main operating conditions were: capillary and cone voltage of $3.00 \mathrm{kV}$ and $20.0 \mathrm{~V}$, respectively; and desolvation temperature of $200{ }^{\circ} \mathrm{C}$. Sample solutions were injected with a continuous flow of $10.0 \mu \mathrm{L} \mathrm{min}{ }^{-1}$. Data were processed using MassLynx ${ }^{\mathrm{TM}}$ software.

\section{Statistical analysis}

The results of fatty acid composition were submitted to analysis of variance (ANOVA) and means were compared using Tukey's test, with a 95\% significance level. Data were processed using PAST3 software. ${ }^{13}$

Principal component analysis (PCA) was performed to verify relationships between samples, to verify possible frauds. The matrices were constructed using data obtained by the GC-FID and processed using the RStudio software. ${ }^{14}$

\section{Results and Discussion}

\section{Fatty acid composition by GC-FID}

The fatty acid compositions of cosmetic samples, their respective pure vegetable oils, and three soybean oils were obtained; the results are presented in Table 2 .

The Codex Standard for Named Vegetable Oils, CX-STAN 210-1999, and amended in 2015, ${ }^{15}$ establishes the ranges of fatty acid composition (expressed in percentage) for some largely commercialized vegetable oils. Among the pure vegetable oils analyzed in this study, all except almond oil are listed in this standard.

For pure vegetable oils, as shown by the results presented in Table 2, it was found that the compositions of sesame, sunflower (mid-oleic-acid), peanut, and soybean oils fatty acids are in accordance with the Codex standards. ${ }^{15}$

Moreover, the results obtained by Orsavova et al. ${ }^{16}$ are in accordance with those obtained for sesame oil. Also, the bibliographic research carried out by Zielińska and Nowak ${ }^{2}$ presents results approximate to those reported in Table 2 for peanut, soybean, and sesame oils.

Previous studies of the oil extracted from sweet almond seeds ${ }^{17,18}$ have demonstrated that the fatty acid composition and its content vary according to the variety and region of almond growth. The study performed by Askin et al. ${ }^{19}$ presents high variation in the sweet almond fatty acid composition, but the percentages described in Table 2 for almond oil are within the range obtained by them.

About cosmetics with a vegetable oil base, we observed that sample S1, a cosmetic with a sesame oil base, presented fatty acid percentages close to those presented by sesame oil. Sample SF2, a cosmetic with a sunflower oil base, showed fatty acid percentages close to those of sunflower oil, as well as according to the ranges established by Codex Alimentarius. ${ }^{15}$ However, cosmetic SF1 was distinct from this oil because it presented a high content of palmitic (16:0), linoleic (18:2n-6), and $\alpha$-linolenic (18:3n-3) acid, and a low content of oleic acid (18:1n-9). It can be seen that the composition of sample SF1 was similar to that of soybean oil samples, indicating that this cosmetic was a possible fraud.

In the peanut body oil sample P2, high contents of linoleic (18:2n-6) and $\alpha$-linolenic (18:3n-3) acid were

Table 2. Fatty acid composition of cosmetics, their related vegetable oils, and soybean oil

\begin{tabular}{|c|c|c|c|c|c|c|c|c|c|}
\hline \multirow{2}{*}{ Sample } & \multicolumn{9}{|c|}{ Fatty acid composition ${ }^{\mathrm{a}} / \%$} \\
\hline & $16: 0$ & 18:0 & $18: \ln -9$ & $18: 2 n-6$ & $18: 3 n-3$ & $20: 0$ & $20: \ln -9$ & $22: 0$ & $24: 0$ \\
\hline Sesame oil & $10.43 \pm 0.22^{\mathrm{H}}$ & $5.87 \pm 0.39^{\mathrm{A}}$ & $42.63 \pm 0.14^{\mathrm{D}}$ & $41.07 \pm 0.24^{\mathrm{G}}$ & $\mathrm{ND}^{\mathrm{F}}$ & $\mathrm{ND}^{\mathrm{B}}$ & $\mathrm{ND}^{\mathrm{C}}$ & $\mathrm{ND}^{\mathrm{B}}$ & $\mathrm{ND}^{\mathrm{B}}$ \\
\hline S1 & $10.45 \pm 0.05^{\mathrm{H}}$ & $4.78 \pm 0.50^{\mathrm{B}}$ & $39.75 \pm 0.77^{\mathrm{E}}$ & $45.01 \pm 0.70^{\mathrm{F}}$ & $\mathrm{ND}^{\mathrm{F}}$ & $\mathrm{ND}^{\mathrm{B}}$ & $\mathrm{ND}^{\mathrm{C}}$ & $\mathrm{ND}^{\mathrm{B}}$ & $\mathrm{ND}^{\mathrm{B}}$ \\
\hline Sunflower oil & $6.22 \pm 0.04^{\mathrm{G}}$ & $3.23 \pm 0.27^{\mathrm{C}}$ & $49.70 \pm 0.19^{\mathrm{B}}$ & $40.85 \pm 0.31^{\mathrm{G}}$ & $\mathrm{ND}^{\mathrm{F}}$ & $\mathrm{ND}^{\mathrm{B}}$ & $\mathrm{ND}^{\mathrm{C}}$ & $\mathrm{ND}^{\mathrm{B}}$ & $\mathrm{ND}^{\mathrm{B}}$ \\
\hline $\mathrm{SF} 1$ & $11.77 \pm 0.07^{\mathrm{C}}$ & $3.59 \pm 0.24^{\mathrm{CD}}$ & $27.29 \pm 0.13^{\mathrm{H}}$ & $52.15 \pm 0.09^{\mathrm{B}}$ & $5.18 \pm 0.05^{c}$ & $\mathrm{ND}^{\mathrm{B}}$ & $\mathrm{ND}^{\mathrm{c}}$ & $\mathrm{ND}^{\mathrm{B}}$ & $\mathrm{ND}^{\mathrm{B}}$ \\
\hline SF2 & $5.13 \pm 0.02^{\mathrm{I}}$ & $3.57 \pm 0.32^{\mathrm{CDE}}$ & $46.35 \pm 0.19^{\mathrm{C}}$ & $44.95 \pm 0.31^{\mathrm{F}}$ & $\mathrm{ND}^{\mathrm{F}}$ & $\mathrm{ND}^{\mathrm{B}}$ & $\mathrm{ND}^{\mathrm{C}}$ & $\mathrm{ND}^{\mathrm{B}}$ & $\mathrm{ND}^{\mathrm{B}}$ \\
\hline Peanut oil & $12.14 \pm 0.09^{A}$ & $2.53 \pm 0.19^{\mathrm{CJ}}$ & $38.77 \pm 0.22^{\mathrm{EF}}$ & $39.38 \pm 0.44^{\mathrm{H}}$ & $1.03 \pm 0.14^{\mathrm{E}}$ & $\mathrm{ND}^{\mathrm{B}}$ & $0.81 \pm 0.03^{\mathrm{A}}$ & $2.43 \pm 0.42^{\mathrm{A}}$ & $2.91 \pm 0.60^{\mathrm{B}}$ \\
\hline P1 & $12.36 \pm 0.11^{\mathrm{A}}$ & $2.65 \pm 0.16^{\mathrm{CDEJ}}$ & $38.26 \pm 0.08^{\mathrm{F}}$ & $37.77 \pm 0.33^{1}$ & $1.17 \pm 0.07^{\mathrm{E}}$ & $1.37 \pm 0.11^{\mathrm{A}}$ & $0.93 \pm 0.05^{\mathrm{A}}$ & $3.08 \pm 0.07^{\mathrm{A}}$ & $2.43 \pm 0.25^{\mathrm{B}}$ \\
\hline $\mathrm{P} 2$ & $11.31 \pm 0.14^{\mathrm{F}}$ & $3.28 \pm 0.10^{\mathrm{CDEFHJ}}$ & $24.65 \pm 0.41^{\mathrm{J}}$ & $51.50 \pm 0.42^{\mathrm{BC}}$ & $5.67 \pm 0.33^{\mathrm{AC}}$ & $\mathrm{ND}^{\mathrm{B}}$ & $\mathrm{ND}^{\mathrm{c}}$ & $\mathrm{ND}^{\mathrm{B}}$ & $3.59 \pm 0.51^{\mathrm{A}}$ \\
\hline Almond oil & $6.84 \pm 0.15^{\mathrm{J}}$ & $1.38 \pm 0.23^{\mathrm{B}}$ & $60.78 \pm 0.18^{\mathrm{A}}$ & $31.00 \pm 0.26^{\mathrm{J}}$ & $\mathrm{ND}^{\mathrm{F}}$ & $\mathrm{ND}^{\mathrm{B}}$ & $\mathrm{ND}^{c}$ & $\mathrm{ND}^{\mathrm{B}}$ & $\mathrm{ND}^{\mathrm{B}}$ \\
\hline $\mathrm{A} 1$ & $11.71 \pm 0.20^{\mathrm{CD}}$ & $4.04 \pm 0.10^{\mathrm{CDEFG}}$ & $25.32 \pm 0.17^{\mathrm{IJ}}$ & $53.56 \pm 0.27^{\mathrm{A}}$ & $5.38 \pm 0.22^{\mathrm{ABC}}$ & $\mathrm{ND}^{\mathrm{B}}$ & $\mathrm{ND}^{\mathrm{c}}$ & $\mathrm{ND}^{\mathrm{B}}$ & $\mathrm{ND}^{\mathrm{B}}$ \\
\hline $\mathrm{A} 2$ & $N^{L}$ & $\mathrm{ND}^{\mathrm{L}}$ & $N^{L}$ & $\mathrm{ND}^{\mathrm{L}}$ & $\mathrm{ND}^{\mathrm{F}}$ & $\mathrm{ND}^{\mathrm{B}}$ & $\mathrm{ND}^{\mathrm{C}}$ & $\mathrm{ND}^{\mathrm{B}}$ & $\mathrm{ND}^{\mathrm{B}}$ \\
\hline Soybean oil SO1 & $11.26 \pm 0.12^{\mathrm{F}}$ & $3.46 \pm 0.53^{\mathrm{CDEFGH}}$ & $29.31 \pm 0.74^{\mathrm{G}}$ & $50.78 \pm 1.03^{\mathrm{CE}}$ & $5.18 \pm 0.36^{\mathrm{ABCD}}$ & $\mathrm{ND}^{\mathrm{B}}$ & $\mathrm{ND}^{\mathrm{c}}$ & $\mathrm{ND}^{\mathrm{B}}$ & $\mathrm{ND}^{\mathrm{B}}$ \\
\hline Soybean oil SO2 & $11.80 \pm 0.05^{\mathrm{ACDE}}$ & $3.93 \pm 0.42^{\text {BCDEFGHI }}$ & $26.01 \pm 0.35^{\mathrm{I}}$ & $52.42 \pm 0.57^{\mathrm{ABCD}}$ & $5.84 \pm 0.18^{\mathrm{AB}}$ & $\mathrm{ND}^{\mathrm{B}}$ & $\mathrm{ND}^{\mathrm{c}}$ & $\mathrm{ND}^{\mathrm{B}}$ & $\mathrm{ND}^{\mathrm{B}}$ \\
\hline Soybean oil SO3 & $11.82 \pm 0.03^{\mathrm{CDE}}$ & $4.20 \pm 0.1^{\mathrm{BCDEFGHI}}$ & $28.02 \pm 0.46^{\mathrm{H}}$ & $51.24 \pm 0.51^{\mathrm{BCDE}}$ & $4.73 \pm 0.09^{\mathrm{CD}}$ & $\mathrm{ND}^{\mathrm{B}}$ & $\mathrm{ND}^{\mathrm{C}}$ & $\mathrm{ND}^{\mathrm{B}}$ & $\mathrm{ND}^{\mathrm{B}}$ \\
\hline
\end{tabular}

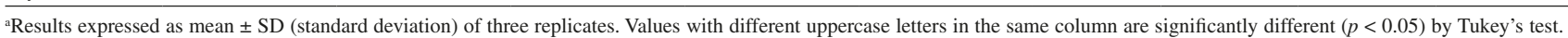
ND: not detected; S1: sesame oil cosmetic; SF1 and SF2: sunflower oil cosmetics; P1 and P2: peanut oil cosmetics; A1 and A2: almond oil cosmetics. 
detected, compared with a pure peanut oil sample, and a low content of oleic acid (18:1n-9), which was similar to the soybean oil samples. Sample P1 presented results similar to its respective oil.

In the sweet almond body oil sample A2, no fatty acid was identified, indicating the existence of mostly mineral oil. In sample A1 (the only sample which the manufacturer reported to contain soybean), high levels of palmitic (16:0), stearic (18:0), linoleic (18:2n-6), and $\alpha$-linolenic $(18: 3 n-3)$ acid, and a low content of oleic acid (18:1n-9), compared with the oil sample extracted directly from seed, were found; this composition is similar to the soybean oil samples.

\section{Chemometric analysis}

To evaluate the ability of the GC-FID technique to classify and discriminate between several types of vegetable oils and cosmetics for fatty acids, PCA was performed. Figure 1 shows the PCA plots of two principal components (PCs); the first principal component (PC1) explained 93.42\% of the variance, while the second (PC2) explained $5.19 \%$. Therefore, PC1 and PC2 explained $98.61 \%$ of the total data variance.

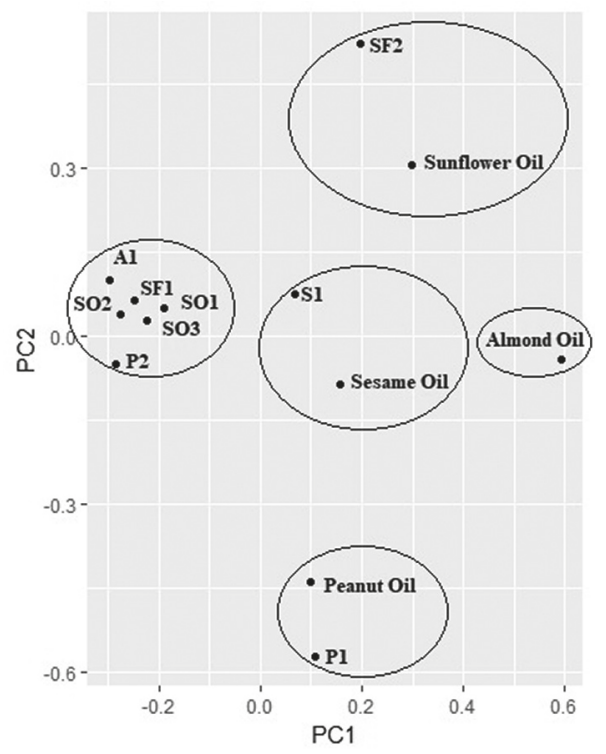

Figure 1. PCA of GC-FID data of the soybean (SO1, SO2, and SO3), peanut, sesame, sunflower, and almond oils, and the cosmetic oil samples of sesame (S1), sunflower (SF1 and SF2), peanut (P1 and P2), and almond (A1) oils.

As observed in Figure 1, PCA clearly separated groups of vegetable oils and cosmetic samples that showed evidence of adulteration with soybean oil, represented by ellipses. Cosmetic samples SF1, A1, and P2 were in the same group of soybean oil samples $\mathrm{SO} 1, \mathrm{SO} 2$, and $\mathrm{SO} 3$, clearly showing that these cosmetic samples contain large quantities of soybean oil in their composition.

Cosmetic samples SF2, S1, and P1 were in the same group as sunflower, sesame, and peanut oils, respectively, illustrating that the samples were not adulterated. Moreover, the PC1 component separated samples with added soybean oil from those of other vegetable sources.

Sample A2 was not included in the PCA because it was not possible to detect the presence of fatty acids during the fatty acid composition analysis by GC-FID (Table 2).

\section{ESI(+)-MS}

Vegetable oils have a characteristic lipid profile, and adulterations, even at low levels, result in significant changes in these profiles, as presented in the studies by Catharino et al., ${ }^{6}$ Cabral et al., ${ }^{7}$ Silveira et al., ${ }^{5}$ and Galuch et al. ${ }^{4}$

To evaluate the lipid profile, TAGs present in ESI(+)-MS were mainly used, because direct infusion analysis and ESI(+)-MS have been used to characterize oils and fats rapidly and with little sample preparation (hydrolysis or derivatization stages are absent), and their lipid profile have revealed information about adulteration. ${ }^{6}$

Figure 2 illustrates the mass spectra of samples of peanut oil and cosmetics $\mathrm{P} 1$ and $\mathrm{P} 2$, comprising the lipid profile in the region of $m / z 700-1020$. It is possible to observe from Figure 2 that peanut oil has a similar lipid profile of cosmetic sample P1, and it is distinct from the lipid profile of the cosmetic P2. This difference is in accordance with the results obtained for the fatty acid compositions, which demonstrates that sample $\mathrm{P} 2$ presents adulteration in its composition.

Figure 3 shows the lipid profile from sesame oil and the cosmetic sample S1. It is apparent that these samples are similar to each other, which confirms their authenticity.

Figure 4 illustrates the lipid profile of almond oil and cosmetic sample A1. It can be observed that these profiles were different from each other, which was predicted from the results of the fatty acid composition. For sample A2, the lipid profile was not monitored, because there was no identification of fatty acids present in the cosmetic material, therefore indicating the absence of TAGs.

Figure 5 shows the lipid profile of sunflower oil and cosmetic samples SF1 and SF2. It is possible to note that the lipid profiles of sunflower oil and cosmetic SF1 were distinct from each other, which was also predicted from the results of fatty acids composition analysis. Sample SF2 demonstrates a profile similar to its respective vegetable oil.

According to the results obtained from GC-FID analysis (Table 2), the fatty acid composition of cosmetic samples 

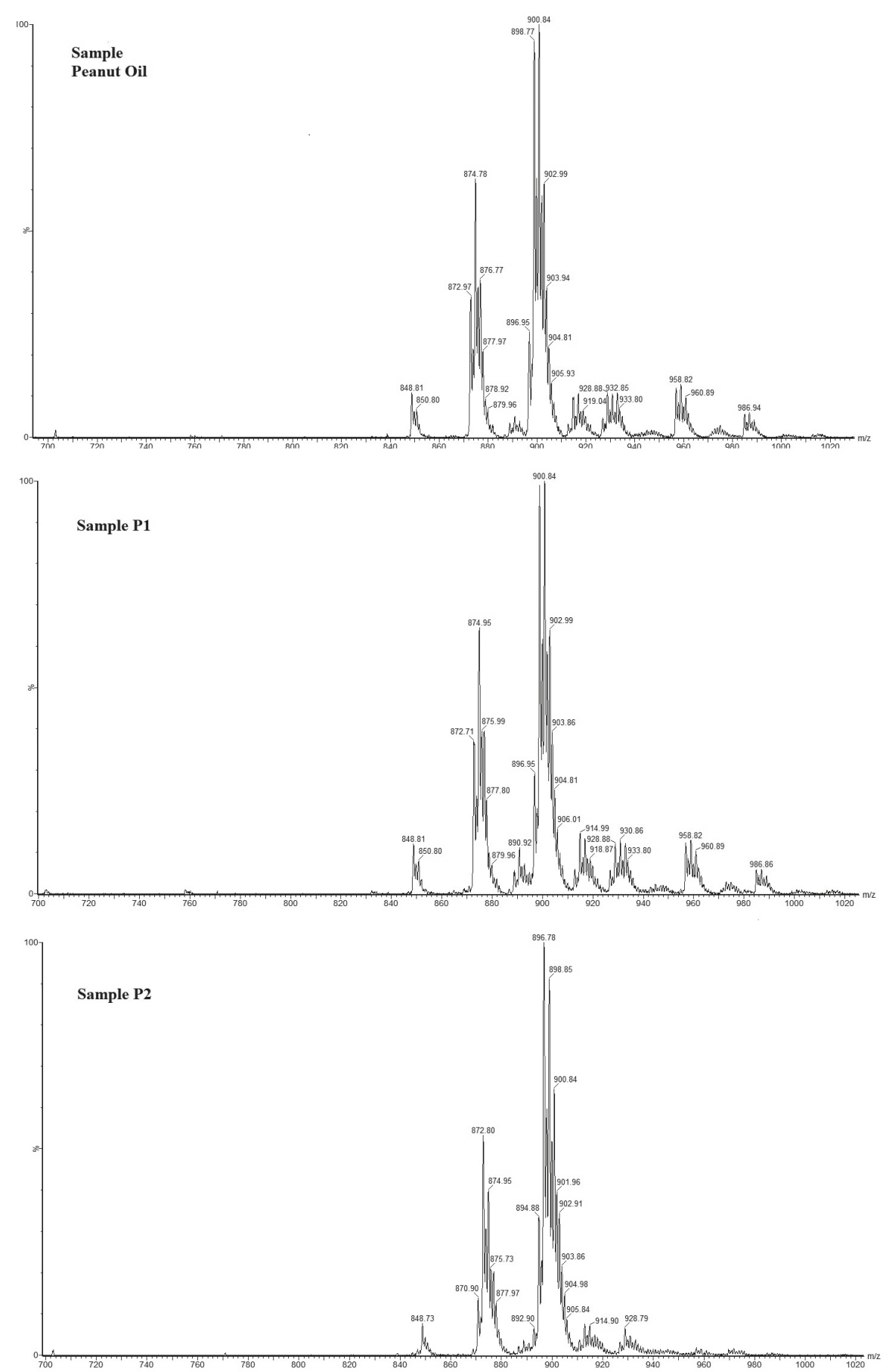

Figure 2. ESI(+)-MS of the peanut oil sample and cosmetic samples P1 and P2.

$\mathrm{P} 2$, A1, and SF1 was similar to the composition of soybean oils $\mathrm{SO} 1, \mathrm{SO} 2$, and $\mathrm{SO} 3$. In addition, the lipid profile of these samples was also different from those presented by their respective vegetable oils (Figures 2, 4, and 5, respectively). Therefore, lipid profiles of soybean oil were obtained and compared with samples P2, A1, and SF1; the results are illustrated in Figure 6. For better visualization, the separate spectra of each sample are available in the Supplementary Information.
Thus, it is observed that samples P2, A1, and SF1 are adulterated with large amounts of soybean oil, because small adulterations would not abruptly modify the lipid profile. ${ }^{4}$

Also, a computational simulation of the probable TAG composition present in different oil samples was carried out, based on the program developed by Antoniosi Filho et al.:20 the results are shown in Table 3 .

From the data presented in Table 3, it can be observed that all pure vegetable oils (sunflower, soybean, sesame, 

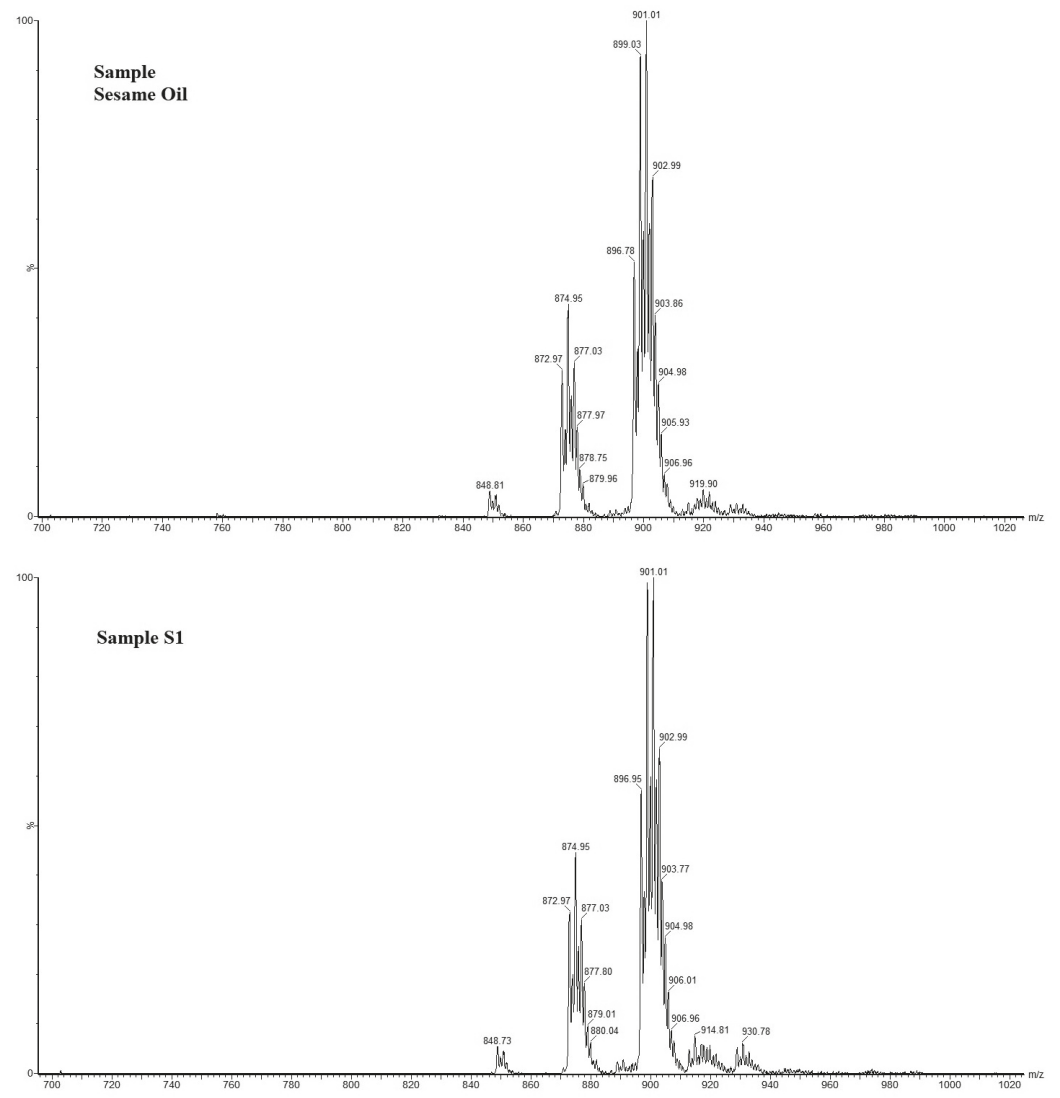

Figure 3. ESI(+)-MS from sesame oil and cosmetic sample S1.
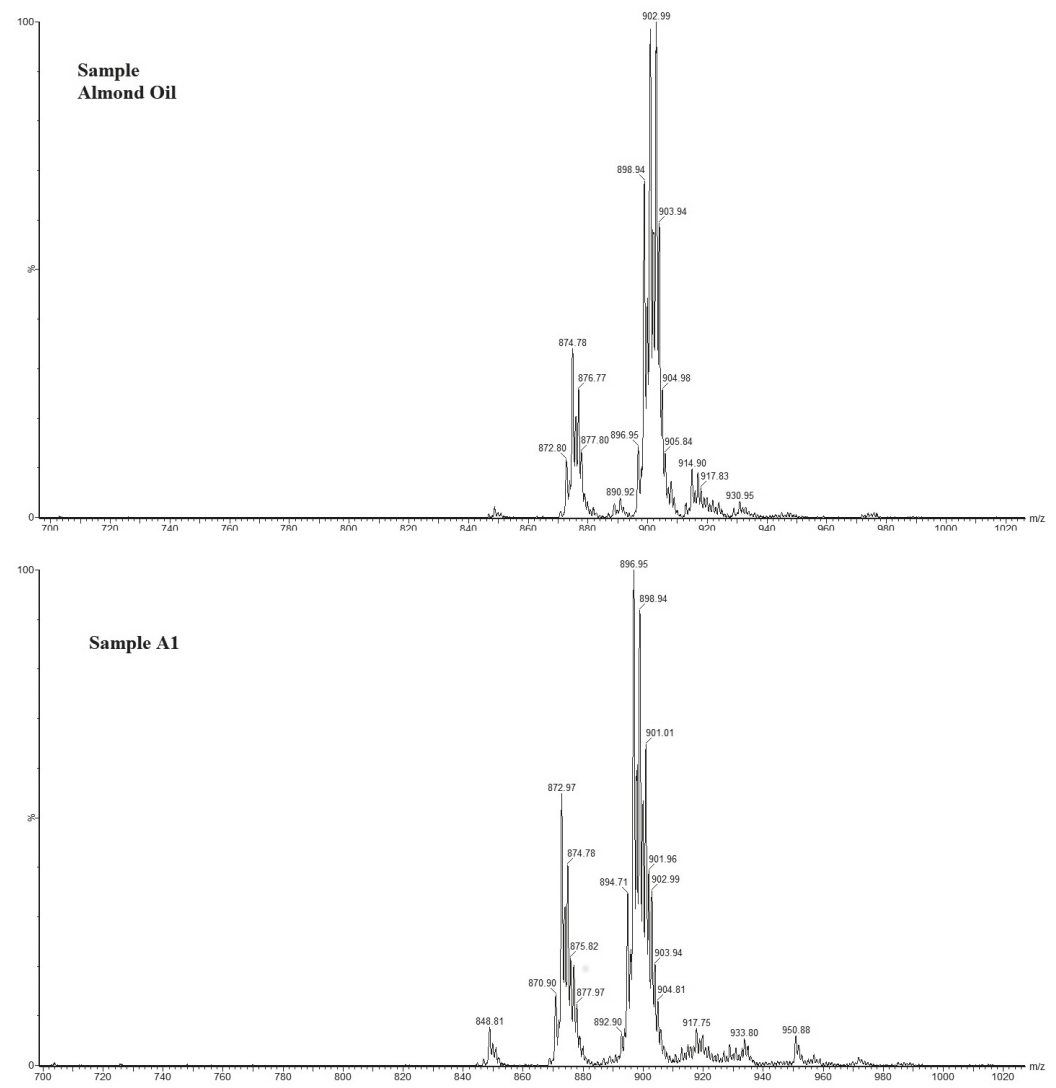

Figure 4. ESI(+)-MS from almond oil and cosmetic sample A1. 
Vol. 29, No. 12, 2018

Puzo et al.

2463
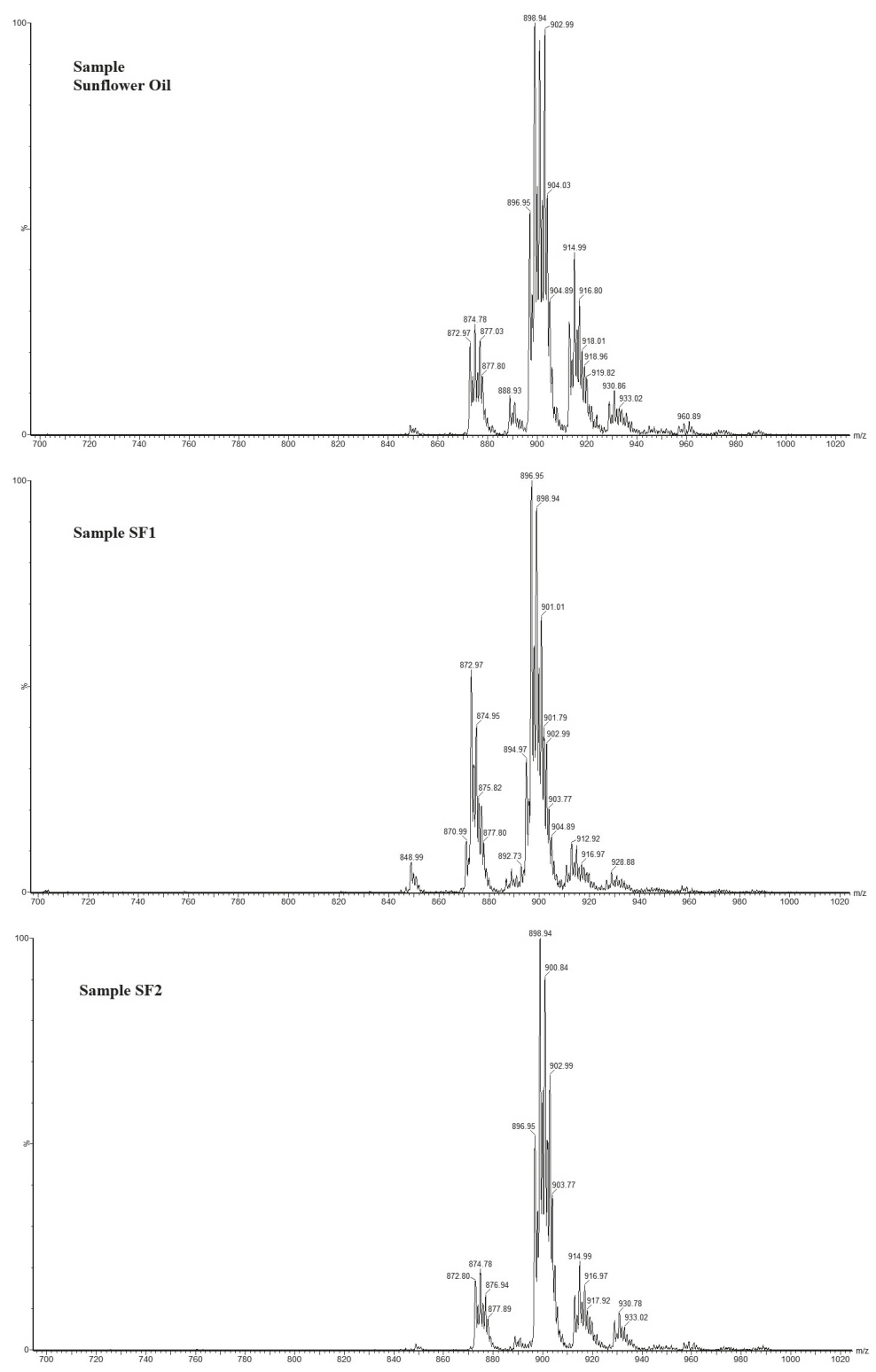

Figure 5. ESI(+)-MS from sunflower oil and cosmetic samples SF1 and SF2.
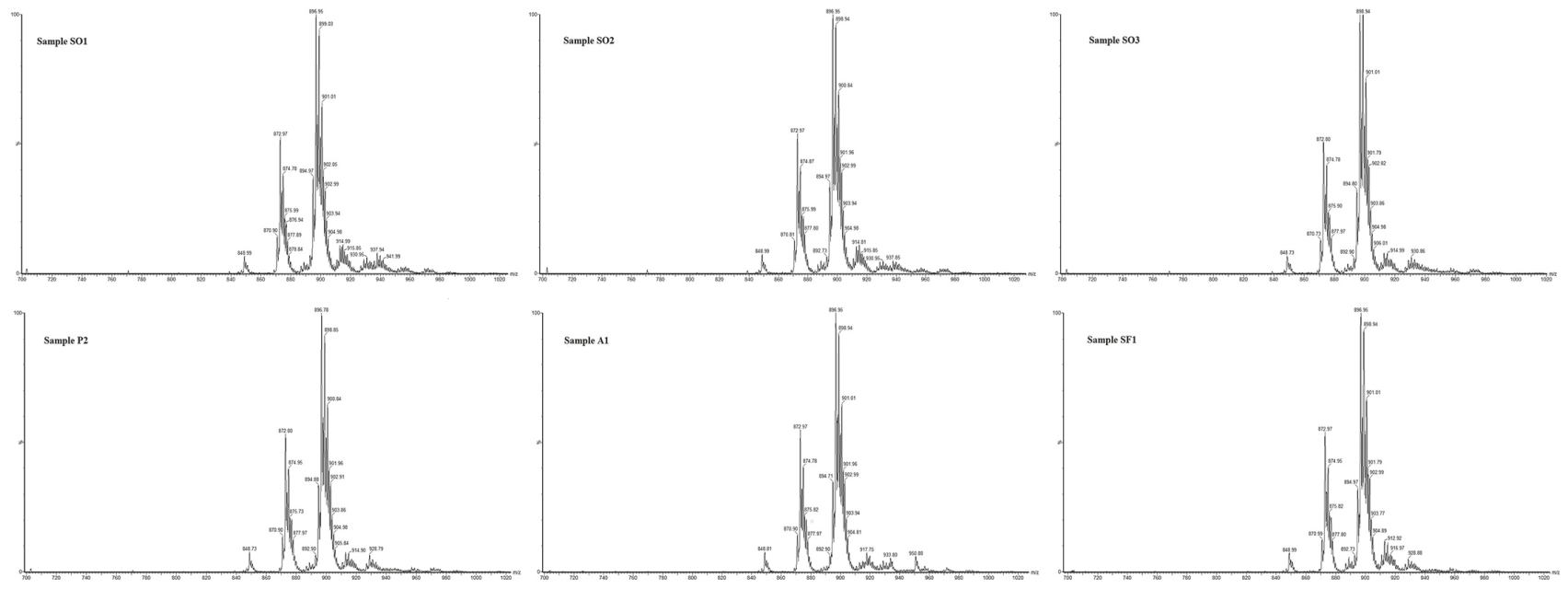

Figure 6. ESI(+)-MS from soybean oil samples (SO1, $\mathrm{SO} 2$, and $\mathrm{SO} 3$ ) and the cosmetics $\mathrm{P} 2$, A1, and SF1. 


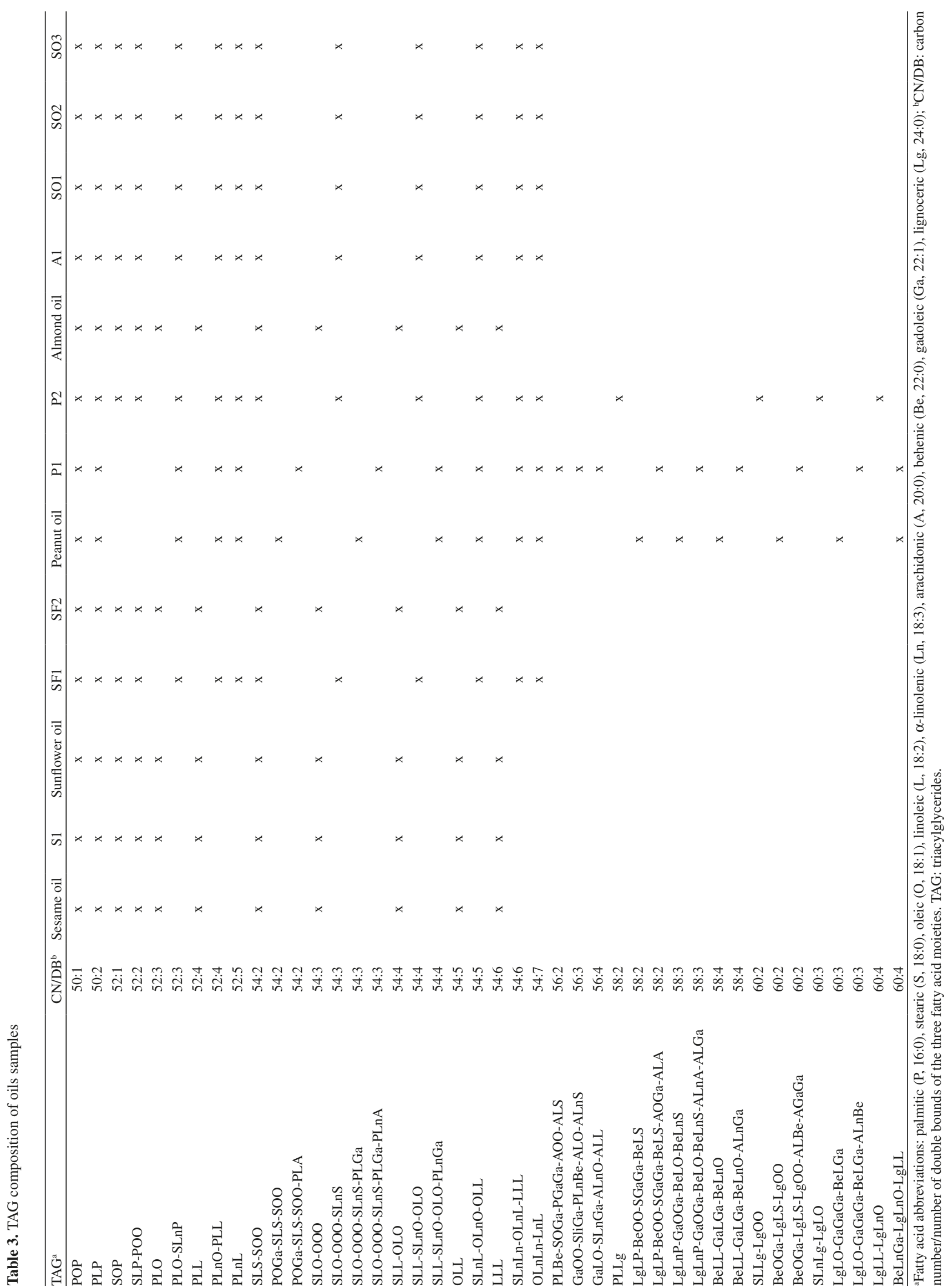


peanut, and almonds) are distinct from each other in TAG composition; that is, it is possible to verify adulterations by monitoring TAGs.

Cosmetics suspected of adulteration with large amounts of soybean oil (SF1, P2, A1 samples) exclusively have TAGs of this oil, and not those that would be expected in pure oils of sunflower, peanut, and almond, respectively. This result is in accordance with the results obtained by GC-FID analysis as well as with the lipid profiles presented by these samples.

Cosmetic samples S1 and SF2 exclusively presented TAGs found in pure sesame and sunflower oils, respectively, in their composition. This result confirms that these cosmetics do not present any adulterations.

\section{Conclusions}

GC-FID analysis, in conjunction with PCA analysis and the direct infusion technique ESI(+)-MS, has been shown to provide a comprehensive evaluation of the lipid composition of vegetable and cosmetic oils. In this study, seven cosmetics based on vegetable oils (sesame, peanut, sunflower, and almonds) were analyzed, comparing them with the respective pure vegetable oils. Vegetable oil was absent from one of the analyzed brands, while adulteration was verified by the addition of large amounts of soybean oil in another three. These results demonstrate the importance of quality control in vegetable oils, as well as in cosmetics based on vegetable oil, which are more susceptible to adulteration owing to their higher cost when compared with soybean oil.

\section{Supplementary Information}

Supplementary data with the spectra of each sample separately are available free of charge at http://jbcs.sbq.org.br as a PDF file.

\section{Acknowledgments}

The authors are grateful to CNPQ, CAPES, and Fundação Araucária for financial assistance.

\section{References}

1. Saraiva, S. A.; Cabral, E. C.; Eberlin, M. N.; Catharino, R. R.; J. Agric. Food Chem. 2009, 57, 4030.

2. Zielińska, A.; Nowak, I.; Chemik 2014, 68, 103.

3. Ozen, B. F.; Weiss, I.; Mauer, L. J.; J. Agric. Food Chem. 2003, 51,5871 .
4. Galuch, M. B.; Carbonera, F.; Magon, T. F. S.; da Silveira, R.; dos Santos, P. D. S.; Pizzo, J. S.; Santos, O. O.; Visentainer, J. V.; J. Braz. Chem. Soc. 2018, 29, 631.

5. Silveira, R.; Vágula, J. M.; Figueiredo, I. D. L.; Claus, T.; Galuch, M. B.; Oliveira, O.; Junior, S.; Visentainer, J. V.; Food Res. Int. 2017, 102, 43.

6. Catharino, R. R.; Haddad, R.; Cabrini, L. G.; Cunha, I. B. S.; Sawaya, A. C. H. F.; Eberlin, M. N.; Anal. Chem. 2005, 77, 7429.

7. Cabral, E. C.; da Cruz, G. F.; Simas, R. C.; Sanvido, G. B.; Gonçalves, L. V.; Leal, R. V. P.; da Silva, R. C. F.; da Silva, J. C. T.; Barata, L. E. S.; da Cunha, V. S.; de França, L. F.; Daroda, R. J.; de Sá, G. F.; Eberlin, M. N.; Anal. Methods 2013, 5, 1385.

8. Ribeiro, S. A. O.; Nicacio, A. E.; Zanqui, A. B.; Biondo, P. B. F.; Abreu-Filho, B. A.; Visentainer, J. V.; Gomes, S. T. M.; Matsushita, M.; LWT - Food Sci. Technol. 2016, 65, 464.

9. Hartman, L.; Lago, R. C.; Lab. Pract. 1973, 22, 474.

10. Maia, E. L.; Rodriguez-Amaya, D. B.; Rev. Inst. Adolfo Lutz 1993, 53, 27.

11. Figueiredo, I. L.; Claus, T.; Oliveira, O.; Júnior, S.; Almeida, V. C.; Magon, T.; Visentainer, J. V.; J. Chromatogr. A 2016, 1456, 235.

12. Youzbachi, N.; Trabelsi, H.; Elfalleh, W.; Khaldi, A.; Nasri, N.; Tlili, N.; Arab. J. Chem. 2015, DOI: 10.1016/j. arabjc.2015.08.020.

13. Hammer, Ø.; Harper, D. A. T.; Ryan, P. D.; Palaeontol. Electronica 2001, 4, 9.

14. R Development Core Team; RStudio, R: A Language and Environment for Statistical Computing; The R Foundation for Statistical Computing, Vienna, Austria, 2017.

15. Codex Alimentarius; Standard for Named Vegetable Oils, Codex Stan 210-1999; Food and Agriculture Organization of thte United States (FAO), World Health Organization (WHO), 2015, p. 1-13.

16. Orsavova, J.; Misurcova, L.; Ambrozova, J. V.; Vicha, R.; Mlcek, J.; Int. J. Mol. Sci. 2015, 16, 12871.

17. Sathe, S. K.; Seeram, N. P.; Kshirsagar, H. H.; Heber, D.; Lapsley, K. A.; J. Food Sci. 2008, 73, C607.

18. Kodad, O.; Estopanán, G.; Juan, T.; Molino, F.; Mamouni, S.; Messaoudi, Z.; Lahlou, M.; Rafel Socias I Company; J. Hortic. Sci. Biotechnol. 2010, 85, 381.

19. Askin, M. A.; Balta, M. F.; Tekintas, F. E.; Kazankaya, A.; Balta, F.; J. Food Compos. Anal. 2007, $20,7$.

20. Antoniosi Filho, N. R.; Mendes, O. L.; Lanças, F. M.; Chromatographia 1995, 40, 557.

Submitted: March 25, 2018 Published online: June 25, 2018 